\title{
Suggestopedi som språkdidaktiskt verktyg i vuxenutbildning - en kritisk textanalys
}

\author{
Anita Norlund \\ Högskolan i Borås, Akademin för bibliotek, information, pedagogik och IT
}

\begin{abstract}
Syftet med den här artikeln är att belysa hur förespråkare för den språkdidaktiska metoden suggestopedi konstruerar 1) problemet med att vuxna med utomeuropeisk språkbakgrund inte lär sig tillräckligt snabbt samt 2) lösningen, det vill säga hur denna problematik kan och bör bemötas enligt involverade projektaktörer. Detta görs genom en kritisk diskursanalys av sex strategiskt utvalda texter som alla framhåller suggestopedi som en fruktbar metod och som alla knyter an till projekt finansierade av Europeiska socialfonden. Analysen genomförs i fem steg. I det första steget identifieras hur problemet med att de vuxna inte lär sig snabbt nog konstrueras av aktörer som är involverade i projekten och i det andra steget identifieras vilka lämpliga åtgärder som föreslås i syfte att adressera det uppfattade problemet. Steg tre packar upp det nätverk av praktiker i vilken Europeiska socialfonden är en central aktör. Därefter belyses motstridigheter och luckor som trädde fram via analysen liksom potentiella metodologiska problem. De slutsatser som går att dra handlar om att det finns kritiska aspekter att beakta både när det gäller hur de vuxna med utländsk bakgrund konstrueras och vad beträffar den tillämpade didaktiska metoden.
\end{abstract}

\section{INLEDNING}

Att lära sig ett andra (eller tredje) språk är komplicerat (se exempelvis Colliander, 2018; Franker, 2004). Att undervisa människor som lär sig ett andra språk kräver därför en hel del av medvetenhet, både ifråga om synsätt och om didaktiska val (Trigwell, Prosser \& Waterhouse, 1999). När det gäller synsätt är det enligt Franker (2004) exempelvis viktigt att undvika ett bristperspektiv på deltagande elever; i själva verket har alla människor språkliga erfarenheter att utgå från. När det i sin tur gäller didaktiska val har 
aktuell forskning också identifierat aspekter som är viktiga att beakta. Undervisning utformas exempelvis bäst om den startar i de vuxna elevernas förkunskaper men inte stannar där utan också tar i beaktande elevernas behov att utveckla de mer komplicerade färdigheter som behövs i samhälls- och arbetslivsdeltagande (se Wedin, Rosén, Rasti \& Hennius, 2016). Också viktigt är att elever tillåts dra nytta av sitt modersmål (Straszer, Rosén \& Wedin, 2020), det vill säga att undervisningen inte hålls enspråkigt svensk. Trots alla de utmaningar som uppdraget innebär har lärare via sin unika maktposition goda möjligheter att stödja elever (Cummins, 2017).

Behovet av verkningsfulla språkdidaktiska metoder tycks ha ökat med de senaste årens invandring parallellt med en önskan om att matcha vuxna med utländsk bakgrund mot arbetsmarknadens behov av arbetskraft. I den här artikeln riktas uppmärksamheten mot en särskild metodik, närmare bestämt suggestopedi. Suggestopedi förekommer inom olika utbildningssammanhang för vuxna, såväl i formell sfi-utbildning anordnad av kommuner som i mer ickeformella som till exempel Svenska från dag ett som anordnas av folkhögskolor. Europeiska Socialfonden (ESF), som ger anslag till projekt och som vill möta ovan beskrivna behov, har visat stor tilltro till suggestopedi som adekvat språkdidaktisk metod. Via sina prioriteringar förmedlar Europeiska Socialfonden ideologiska normer och utövar därmed makt. Tidigare forskning har främst framhävt fördelarna med suggestopedimetoden vilket innebär att ett granskande perspektiv också torde ha sin plats. Dessa omständigheter utgör sammantaget motiv för föreliggande studie vars syfte är att kritiskt belysa resonemang från förespråkare för suggestopedi som undervisningsmetod.

Suggestopedimetoden utvecklades av den bulgariske psykoterapeuten Georgi Lozanov på 70-talet och har främst använts för lärande av främmande språk. Följande citat bidrar med information om metoden som i nutid också har de alternativa benämningarna accelerated learning eller accelerative learning:

Accelerated learning. First called suggestopedia (Lozanov, 1978), this adult learning method includes procedures for creating a relaxed emotional state, an orchestrated and multi-sensory learning environment, and active learner engagement in the learning process (Meier, 2000). A relaxed emotional state includes relaxation and breathing exercises, suggestion, and a positive learning atmosphere. An orchestrated environment includes imagery, dramatic readings, instructional videos, and peripherals (posters and visual displays). Active learning includes plays or skits, role playing, practice exercises, group activities, and journal writing. Accelerated learning is considered a holistic adult learning method that is intended to promote creation (and not consumption), enhance retention, and quicken the learning process. (Trivette, Dunst, Hamby \& O’Herin, 2009). 
En avslappnad miljö är alltså en av flera viktiga principer i metoden och holism en andra. Zaid (2014) behandlar båda dessa och lägger till 'lärande i grupp' som en tredje. Det multisensoriska är ett annat element som lyfts fram, både av Trivette, Dunst, Hamby och O'Herin (2009, se citatet ovan) och av Imel (2002). Tanken som innebär att elever har behov av att bli bemötta med hänsyn tagen till deras olika lärstilar; "auditory, visual and kinesthetic experiences" (James, 2000, s. 104) ingår också (det problematiska med lärstilsfenomenet kommer att behandlas i resultatsteg 4).

Mateva (1997) sympatiserar med metoden och beskriver fördelarna med att undervisningen startar första dagen med ett rollspel:

They [the students] instantly forget about their barriers and their problems (teachers need it no less than students) and plunge deep into a new reality which they create step by step through the means of the foreign language. (s. 27).

Ett exempel på suggestion, det vill säga på det fenomen som har namngett metoden, är att berörda elever möts med försäkringar av typen: "Idag kommer det att gå lätt för dig att lära" (Schuster \& Gritton, 1986, min översättning). Infantilisering, som lätt skulle kunna uppfattas som något negativt, betonas i den suggestopediska traditionen istället som något positivt:

For comparison, infantilisation in suggestopedia creates reliance, removes pressure and creates an encouraging atmosphere for fighting overt selfconsciousness (Lozanov 1978, s. 192-193 se Leino, 2017, s. 175).

Infantilisering ingår alltså som ett element som bidrar till en särskild typ av atmosfär, en suggestopedisk sådan.

\section{ATTITYYDER TILL METODEN I FORSKNING}

Tidigare studier tycks ha betonat metodens fördelar, vilket kan avläsas av föregående stycke som tog upp positivt laddade fenomen som en avslappnad miljö, holism och möjlighet till individuella anpassningar. Endast ett fătal studier har intagit ett kritiskt perspektiv. Bland dessa hittar vi Scovel (1979) som redan för flera decennier sedan kallade metoden för pseudovetenskap. Metodens uteblivna effekter har behandlats av Shimbo (2008) som bygger sin slutsats både på tidigare forskning och på egna studier. Vid sidan av sina sympatier med metoden listar Mateva (1997) också en del nackdelar, fortfarande med särskilt fokus på rollspel, en aktivitet som författaren menar att inte alla tilltalas av. Annat problematiskt som Mateva lyfter fram är att metoden är tidskrävande för lärare som inte alltid tycker sig se resultat och att 
språket riskerar att bli "either oversimplified and impoverished (frequently accompanied by violent gesticulation) or too elaborate and artificial" (s. 29).

\section{TEORI OCH METOD}

Kritisk diskursanalys utgör angreppssättet $\mathrm{i}$ den här artikeln. I det här sammanhanget definieras diskurs som en "way of signifying experience from a particular perspective" (Fairclough, 1995, s. 135). Två fenomen är särskilt intressanta för den kritiska diskursanalysens tradition; dels vikten av att göra språkliga analyser, dels vikten av att beakta att språk och makt hör samman. Detta är angeläget att ha $\mathrm{i}$ åtanke eftersom Europeiska Socialfonden, vilket redan har nämnts, genom sina prioriteringar och i sin roll som förmedlare av ideologiska normer, såväl uppåt som neråt (jfr Ayers, 2005), utövar makt. På så vis intar fonden en roll som innebär att förstärka (eller försvaga) specifika värden (jfr Guo \& Shan, 2013, s. 464).

Artikelns mer preciserade syfte är att med hjälp av kritisk diskursanalys analysera texter där representanter för suggestopedimetodiken konstruerar 1) ett problem, närmare bestämt problemet med att vuxna med utomeuropeisk språkbakgrund inte lär sig det nya språket tillräckligt snabbt samt 2) lösningen, det vill säga hur denna problematik kan och bör bemötas enligt involverade projektaktörer. Med projektaktörer avses såväl Europeiska Socialfonden som involverade projektledare och lärare.

\section{Urval}

Den här studien startade på Europeiska socialfondens hemsida med hjälp av sökordet suggestopedi. Sökningen ledde till följande träffar och texter:

- Text 1 berör projektet KNUT som har bedrivits mellan 2011 och 2014 och med finansiellt stöd om 11470999 kronor från Europeiska Socialfonden. Projektet har en filmprofil. Texten finns på en sida med ESF-fondens logotyp och EU-flaggan. Texten benämns i fortsättningen ESF-text 1. ${ }^{1}$

- Text 2 utgörs av en sammanfattning som hänvisar till projektet SSI Suggestopedisk SpråkInlär. Projektet startade 2017 och som avslutas 2019. Projektbudgeten omfattar 5672548 kronor från Europeiska Socialfonden. Texten, som också den omgärdas av ESF-fondens logotyp och EU-flaggan, förkortas här ESF-text 2. ${ }^{2}$

- Text 3 är knuten till ytterligare ett projekt, Gröna gången, som har en profil mot ["a]ktiviteter inom gröna näringar och andra hälsoinspirerande aktiviteter". Projektet pågår 2018 till 2021 och beviljat stöd från Europeiska socialfonden är 13553273 kronor. 
Texten som har samma semiotiska resurser som ovanstående texter betecknas ESF-text $3 .^{3}$

Samtliga projekt är placerade i Östra Mellansverige och samtliga har haft som syfte att förbättra villkoren för vuxna utrikesfödda. Det framgår inte tydligt om suggestopediprojekten genomförs inom ordinarie SFI-verksamhet eller utanför men det senare alternativet framstår som mest troligt.

De tre valda texterna som listas ovan innehåller få konkreta beskrivningar av hur suggestopedimetoden realiseras och därmed hur lösningar konstrueras (se artikelns delsyfte). För att också få en bild av hur suggestopedimetoden beskrivs och realiseras $\mathrm{i}$ de berörda kommuner som har fått anslag av Europeiska socialfonden valdes därför ytterligare tre texter:

- Text 4 har titeln De dansar och smakar på verben och är publicerad i Lärarförbundets Tidningen Grundskolan (14 januari 2013). Artikeln har ett tydligt fokus på att beskriva hur metoden realiseras av den suggestopedicertifierade språklärare ${ }^{4}$ som intervjuas. Texten som innehåller ett par färgbilder benämns Realtext 1.5

- Text 5 har titeln Lekfullheten har gjort lärandet lättare och är publicerad i Katrineholms-Kuriren (18 juni 2018). Den är bildsatt med flera färgbilder. Texten benämns Realtext $2 .{ }^{6}$

- Text 6 består av två instagraminlägg där suggestopedimetoden är i fokus (https://deskgram.net/gronagangen den 17 april 2019 och 13 juni 2019). Texten betecknas i fortsättningen Realtext 3 .

Sex texter ingår således i urvalet som den kommande analysen bygger på.

\section{Analysmetod}

De utvalda texterna har analyserats efter en fempunktslista. Listan kombinerar de fem steg som den kritiske diskursanalytikern Fairclough (2003, s. 209-210) har satt upp i en av sina många analysnycklar med en modifiering gjord av Guo och Shan (2013), två kanadensiska forskare som återkommande har tillämpat kritisk diskursanalys inom en faircloughsk tradition med fokus på policy, texter och migration.

Det slutliga tillvägagångssättet (se också Levinsson \& Norlund, 2018) följer följande steg:

1. Fokusera på ett socialt problem som har en semiotisk aspekt. Analysera hur problemet framställs/konstrueras. Identifiera vilken diskurs/vilka diskurser som är involverad/-e.

2. Analysera hur föreslagna åtgärder framställs/konstrueras. Identifiera vilken diskurs/vilka diskurser som är involverad/-e. 
3. Kartlägg vilket nätverk av praktiker som problemet och åtgärderna bygger på, samt hur relevanta praktiker eventuellt omorganiseras. Fundera över huruvida nätverket av praktiker ('the social order') "behöver" problemet.

4. Identifiera eventuella motstridigheter och luckor i materialet. Ge plats för motröster.

5. Reflektera kritiskt över analysen (steg 1-4)

De texter som är valda är i linje med steg 1 ; samtliga valda texter ger uttryck för ett problem. I det här fallet handlar problemet enligt texterna om en grupp människor som har svårigheter med att lära sig svenska och att villkoren för deras möjligheter att lära behöver förändras. Alla texter drar därtill (självklart) nytta av semiotiska resurser. Exempelvis finns numrerade punktlistor (ESFtext 1), hel mening skriven med versaler (ESF-text 2) och färgfoton (Realtext 1, 2 och 3). Antagandet enligt multimodalitetsteori är att olika resurser i kombination ger vissa signaler till läsaren (se Kress \& van Leuween, 2006) och att dessa därmed är viktiga att beakta.

Analysredskapet, eller snarare de varianter som tidigare har tillämpats, har lagt olika tyngdpunkt vid det lingvistiska. Till exempel har Guo och Shan (2013) fokuserat mindre på det lingvistiska medan Brooks (2003) som ansluter sig till den systemisk-funktionella lingvistiken (SFL) (Halliday, 1994) gjort det i högre grad. Likt Brooks ansluter jag mig här till SFL som är "en textnära, betydelsefokuserad och social teori som inspirerar till kritisk språkreflektion" (Holmberg \& Karlsson, 2006, s. 9). För denna analys betyder det att närstudera språket $i$ ett urval av texter för att se vilka konstruktioner det bidrar med. SFL knyter alltså an till de kritiska utgångspunkter som vi hittar hos Fairclough.

De valda texterna har övergripande analyserats med hjälp av en transitivitetsanalys (se Holmberg \& Karlsson, 2006) och kategoriserats via begrepp som förstadeltagare, processer, andradeltagare och omständigheter. Processer står för det som "görs, känns, sägs eller finns" (s. 75) och förstadeltagaren är $\mathrm{den} / \mathrm{det} / \mathrm{de}$ som processen tar sin utgångpunkt i. Andradeltagaren är i sin tur $\mathrm{den} / \mathrm{det} / \mathrm{de}$ som berörs av eller förbinds med förstadeltagaren via processer. När det gäller omständigheter är det i den här studien främst kausala samband som är av intresse, också det ett fenomen som Fairclough lägger stor vikt vid. Som exempel på en omständighet kan ges:

... eftersom de [deltagarna] kört fast i den traditionella undervisningen.

(Realtext 2).

Förstadeltagaren/-tagarna i raden ovan är de involverade vuxenstuderande som därmed som grupp blir representanter för det problematiska (jfr del 1 av föreliggande syfte). 
En formulering av typen:

... Den [metoden] bygger på att sätta elevernas alla sinnen i arbete och skapa en lekfull lust till lärandet. (Realtext 2)

... relaterar till "hur och av vem denna problematik kan och bör bemötas i undervisningen" (jfr del 2 av föreliggande syfte). Förstadeltagaren är här 'metoden' som blir svaret på vem (i det här fallet vad) som ska bemöta problematiken, samtidigt som "att sätta elevernas alla sinnen i arbete och skapa en lekfull lust till lärandet" besvarar bur (omständighet).

Ytterligare några företeelser kommer att ingå i analysen. Hit hör modalitet (uttryck för sanningsgrad), graderingar (uttryck för hög eller låg grad) och metaforer. I kommande resultatdel kommer det att gå att utläsa närmare hur analysen har gått till. Att det finns olika typer av processer ${ }^{7}$ kommer också att framgå. Avsikten är att låta resultatdelen kännetecknas av en transparent analys.

\section{RESULTAT}

Guo och Shan (2013) har alltså inspirerat till analyspresentationens organisation som bygger på de fem, tidigare presenterade, stegen.

\section{Steg 1 - Hur definieras problemet?}

I de studerade texterna framställs tydligt ett antal problem. Ett av dessa problemteman är deltagarnas brister. I ESF-text 1 förknippas deltagarna med hindrande faktorer som "brist på sociala kontakter", "brist i svenska språket", "ohälsa" och "att de saknar färdigheter som arbetsgivare ser som nödvändiga för att uppnå anställningsbarhet". Det negativt orienterade ordvalet (det vill säga "brist", "brist", "o-" och "saknar") förstärks av att de fyra faktorerna presenteras i en 'punktlista'. Den vertikala uppradningen förstärker att deltagarna har en rad brister. Det är därmed följdriktigt just deltagarna som är förstadeltagare i de textdelar som behandlar problemet:

En stor del av dem som idag står utanför arbetsmarknaden och har försörjningsstöd är personer som har olika typer av svårigheter och/eller dyslektiker och har inte haft goda förutsättningar att lära sig det svenska språket ... (ESF-text 1, huvuddeltagaren fetstilad)

De har ingen studieteknik och vet inte hur de ska göra för att lära sig. (Citat, lärare i Realtext 2, förstadeltagaren fetstilad, relationell process festilad och kursiverad). 
Ibland förläggs problemet till deltagarna även $\mathrm{i}$ de fraser där de utgör andradeltagare:

... de hinder som skapas för deltagare som inte tagit till sig det svenska språket. (ESF-text 1, andradeltagare festilad)

... ge människor, med ibland obefintligt självförtroende och negativ självbild ... (ESF-text 3, andradeltagare festilad, det underförstådda 'har' representerar en relationell process).

Det bekymmersamma understryks också av drastiska formuleringar. Även om ordet 'ibland' i citatet ovan synliggör låg modalitet så förstärks det därefter i frasen "obefintligt självförtroende" (modalitet fetstilad) och om deltagarna sägs att "[d]e har ingen studieteknik och vet inte hur de ska göra för att lära sig" (citat lärare i Realtext 2, modalitet fetstilad).

Anledningen till problemet uttrycks i kausala samband, det vill säga i vad man ser som logiska relationer:

Det [övningsurvalet] passar dessa elever bra eftersom de kört fast i den traditionella undervisningen. (Realtext 2, kausalitet fetstilad, mental process fetstilad och kursiverad).

En stor del av problemen ställs i kontrast till den traditionella pedagogiken:

Många som deltar $\mathrm{i}$ traditionell SFI-undervisning känner att de misslyckas och allt fler hoppar av utbildningen. (ESF-text 2, mental process fetstilad)

De har tragglat med svenskan utan att komma någonstans. (Realtext 2, mental process festilad $\left.{ }^{8}\right)$.

Den problematiska traditionella undervisningen beskrivs med ordval som "knastertorrt" (Realtext 1). En intervjuad lärare kontrasterar därtill suggestopedimetoden mot sin egen "språklärare som var som Caligula" (Realtext 1) och i traditionell undervisning används, hävdas det kritiskt, "främst bara de logiska och analytiska" egenskaperna (ESF-text 2).

För att beskriva det problematiska används metaforer, ofta spatiala sådana, som att deltagarna "står utanför arbetsmarknaden", att det finns ett behov av att "föra dem närmare arbetsmarknaden" (båda ESF-text 1) eller se till att de kan "komma in på den svenska arbetsmarknaden" (ESF-text 3). Deltagarna har dessutom alltså "tragglat med svenskan utan att komma någonstans" samt "kört fast i den traditionella undervisningen" (båda Realtext 2). Det hänvisas också implicit till den spatialt orienterade omständigheten "när människor tappat fotfästet i livet" (ESF-text 3). 
I konstaterandet om att eleverna inte har "tagit till sig det svenska språket" (ESF-text 1) syns återigen en mental process (fetstilad). Eftersom det är eleverna som utgör förstadeltagarna är det också dessa som behäftas med mentala, intellektuella eller emotionella brister. Att en av målsättningarna är att "de orkar och vill ta tag $\mathrm{i}$ sitt liv med egen försörjning och ett självständigt liv" (ESF-text 2) förstärker denna iakttagelse. Parallellt med att problem förläggs hos deltagarna finns också ett uttalat eget ansvar hos den ansökande kommunen, uttryckt via en frömetafor:

Vi lyckas inte riktigt hitta de frön som finns inom varje människa att växa och mogna. (ESF-text 3)

Ett ansvar utanför den enskilda individen syns också i uttalandet:

Kommunen, Landstinget, Försäkringskassan och Arbetsförmedlingen har under många år haft olika samverkansprojekt runt denna grupp. Trots detta så lyckas vi dåligt med denna grupp./.../Vår erfarenhet visar att det just nu finns ett glapp i kedjan för att stötta dessa människor. (ESF -text 3)

Här används en metafor om ett "glapp i kedjan", uttryckt i en relationell process (finns). Att denna metafor saknar förstadeltagare minskar emellertid det tidigare uttryckta ansvaret hos de nämnda aktörerna, det vill säga kommunen, landstinget, försäkringskassan och arbetsförmedlingen.

I det här läget av analysen är det dags att fastställa den diskurs som framställningen av problemet bygger på. Vad de aktuella deltagarna beträffar kan det sammanfattningsvis identifieras en bristdiskurs. En liknande bristdiskurs kring vuxna invandrare fann för övrigt Vesterberg (2015) liksom Norlund Shaswar (2014). Vad själva undervisningen beträffar poängterar Rosén (2014) att sfi-undervisning under flera decennier har präglats av en bristdiskurs. Den här analysen visar att undervisningens problem mer precist ryms inom en traditionalitetsdiskurs.

\section{Steg 2 - Hur hanteras problemet?}

Föreslagna åtgärder visar hur problem belysta $\mathrm{i}$ steg 1 bör bemötas. Här återfinns konstateranden som:

Med denna lättsamma och stressfri [sic] språkträning har vi nu under hösten fått följa våra deltagares fantastiska steg mot en bättre svenska ... (Realtext 3, omständighet fetstilad)

Den valda språkträningen är som synes medlet med vilket man ska möta problemen. Språkträningen har egenskaperna 'lättsam' och 'stressfri', ett ordval med positiva konnotationer. Resultatet, det vill säga att deltagarna nu 
har tagit betydelsefulla steg, förstärks med ordet 'fantastiska'. I linje med det lättsamma poängterar ESF-text 2 "att man ska ha roligt samtidigt som man lär sig ett språk". Den sammantagna bild som framträder är tydligt baserad på det lustfyllda, inte minst noterbart i de metaforer som återfinns i materialet:

Efter ett läsår med suggestopedi som lustfylld lärmetod står dörren till nya hemlandets språk på glänt. (Realtext 2)

Detta faktum står i kontrast till de problem med traditionell pedagogik som behandlades under föregående rubrik (och som exempelvis beskrevs som knastertorr).

Det lekfulla draget syns också i ett par mer detaljerade exempel:

Just idag heter hon [läraren] förresten inte Annette. När hon stiger in i klassrummet förvandlas hon till Jacqueline, en konstnärlig fransyska, som för några år sedan blev förälskad i den stilige svensken Magnus, som finns avbildad på ett fotografi mitt på bordet. (Realtext 1)

Därför får de varsitt bagagemärke i handen. För nu är klassrummet en flygplats fulle med vilsekomna resväskor att begära ut. In på detta skådespels scen applåderas "Sångerskan Jill". Hon bär chic boa och solhatt och visar eleverna hur taggen ska användas. (Realtext 2)

Aktiviteterna i ovanstående två citat illustreras via bilder och ett av de två Instagraminläggen (Realtext 3) visar bilder på glada deltagare i en miljö där det lekfulla representeras av färgglada ballonger. Bilder förstärker alltså metodens underhållande kännetecken.

De konkreta didaktiska aktiviteter som nämns i de valda texterna presenteras nedan i tabell 1. Tabellen ger ytterligare exempel på hur det lekfulla prioriteras; man dansar in oregelbundna verbformer och leker kollektiva lekar med bollar och stolsbyten. Tabellen visar också att en variation av aktiviteter förekommer; från ämnesnära fenomen som 'prosodiövningar' till sådana som är mer löst kopplade till språkundervisning, som exempelvis 'isaktivitet'.

Tabell 1. Sammanställning över det didaktiska innehall som nämns i texturvalet.

\begin{tabular}{|l|l|}
\hline Text & Nämnda didaktiska aktiviteter eller innehåll \\
\hline ESF-text 1 & - \\
\hline ESF-text 2 & $\begin{array}{l}\text { • Rollspel } \\
\bullet\end{array}$ \\
\hline ESF-text 3 & - \\
\hline
\end{tabular}




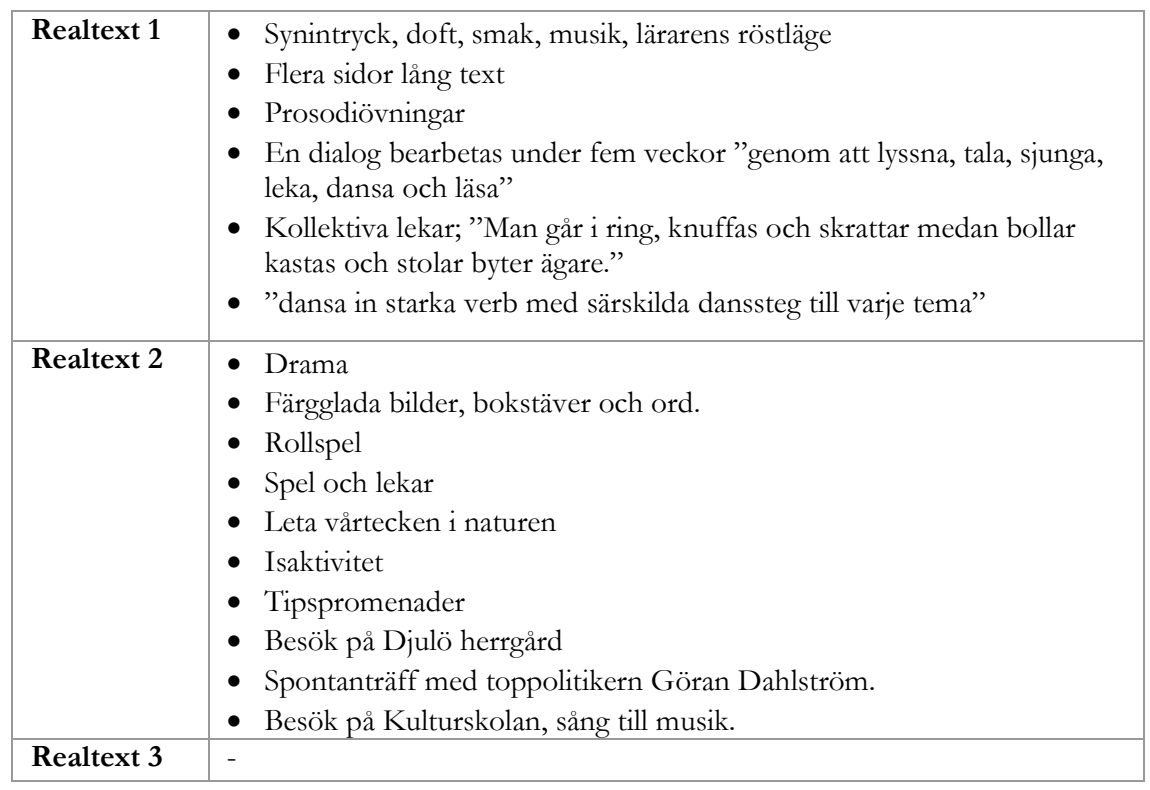

Aktiviteterna som handlar om att leta vårtecken $\mathrm{i}$ naturen eller vara på isutflykt (se tabell 2) visar släktskap med Guos (2010) iakttagelse, närmare bestämt att insatser för vuxna i multietniska samhällen alltmer kännetecknas av att lära invandrare värdlandets normer och värden.

Det finns en mängd satser byggda runt relationella processer som anger vad valda åtgärder leder till. Suggestopedimetoden intar här inte sällan förstadeltagarplatsen. Bland dessa hittas:

I och med att metoden innebär att alla från första början deltar aktivt utifrån sina egna förutsättningar och egenskaper skapas en positiv och lustfylld atmosfär, där alla deltagare känner att de kan lyckas. Resultatet blir en snabbare och bättre inlärning samt ett ökat självförtroende. (ESFtext 2 , relationella processer fetstilade).

Via relationella processer fastslås vad metoden leder till. ESF uttrycker sig alltså med en tvärsäkerhet om kausala samband, för övrigt också via ordet 'skapas'. I tillägg till detta utnyttjas hög modalitet för att förstärka säkerheten; de positiva effekterna gäller 'alla deltagare' (modalitet fetstilad).

Medan metoden intar en tydlig roll blir nu deltagarna via en passivsats istället mer osynliga:

... där [i utbildningen] det största och viktigaste steget har tagits. Att våga prata. (Realtext 3) 
Att deltagarnas första steg handlar om att 'våga', en mental process, innebär att de återigen kategoriseras som en grupp med emotionella brister.

Sammanfattningsvis poängteras de alternativa metodernas betydelse både återkommande och med starkt eftertryck. Ett konstaterande lyder:

Det finns därför behov av att använda alternativa undervisningsformer som gör att alla uppnår den språknivå som krävs för att komma in på den svenska arbetsmarknaden. (ESF-text 2)

Det är tydligt att de olika representanterna för suggestopedimetoden ger löfte om lösningar. Att löftena delvis uttrycks i relationella processer (blir, finns, är) innebär att något slås fast utan förbehåll. Av detta framgår att texten inte har vetenskapens drag av låg modalitet med därpå följande utrymme för problematisering. Istället hörs genklanger av annonser (jfr fraser som "X ger din hy en bättre lyster"). Det indikerar en reklamdiskurs. Det är en av de diskurser som lösningen på den problematik som identifierats bygger på. Den andra diskursen är en lekfull antitraditionalitetsdiskurs där det icke-traditionella består i vissa metoder och attityder. En sådan kan antas vara attraktiv; få vill representera en enformig och gammaldags pedagogik.

\section{Steg 3 - Nätverk och reorganisering}

Detta analytiska steg åskådliggör att lösningsdiskursen om det alternativa och det lustfyllda innefattar ett flertal aktörer.

Tabell 2. Sammanställning över de aktörer som texturvalet hänvisar till och som är involverade $i$ att ge suggestopedimetodiken företräde.

\begin{tabular}{|l|l|l|l|}
\hline & Projekt 1 & Projekt 2 & Projekt 3 \\
\hline Myndighetsnivå & $\begin{array}{l}\text { Europeiska } \\
\text { socialfonden }\end{array}$ & $\begin{array}{l}\text { Europeiska } \\
\text { socialfonden }\end{array}$ & $\begin{array}{l}\text { Europeiska } \\
\text { socialfonden } \\
\text { Arbetsförmedlingen } \\
\text { Försäkringskassan }\end{array}$ \\
\hline Regional nivå & & $\begin{array}{l}\text { Östra Mellansverige } \\
\text { Samordningsförbund } \\
\text { et RAR }\end{array}$ & $\begin{array}{l}\text { Länsstyrelsen } \\
\text { Kommunal nivå }\end{array}$ \\
\hline Skol- & $\begin{array}{l}\text { SF-enheterna i } \\
\text { Eskilstuna och } \\
\text { Katrineholms } \\
\text { kommuner } \\
\text { /klassrumsnivå }\end{array}$ & SFI:s rektor & Sala kommun \\
\hline Övriga & $\begin{array}{l}\text { Någon som utbildar } \\
\text { och certifierar }\end{array}$ & $\begin{array}{l}\text { Katrineholms- } \\
\text { Kuriren } \\
\text { Viadidakt }\end{array}$ & \\
\hline & & & \\
\hline
\end{tabular}


Det finns ytterligare en nivå som berörs och det är forskningsnivån. Denna berörs dock inte på det förväntade viset, nämligen att forskningsproducerad kunskap om suggestopedimetoden involveras. Ett av projekten ska utvärderas "av personer med forskningskompetens" (ESF-text 2) och enligt Realtext 2 är det Linköpings universitet som är det aktuella lärosätet.

För nätverksfrågan är ytterligare ett par saker värda att notera. Den ena är att projektledningen för ESF-projekt 3 föreläser för ett projekt i Norberg, det vill säga de är en spridningsaktör. Det innebär att inte bara Europeiska Socialfonden är en så kallad nodal aktör, det vill säga en aktör med stort nätverkskapital (se Ball, 2016).

Projektens relation till forskning är ambivalent. I Realtext 2 anges att metoden inte är "evidensbaserad, vilket rektor och klasslärarna hoppas att studien ska ändra på”. Rektor välkomnar forskning på verksamheten och att experter kommer med en distanserad blick. Den motsvarande ESF-texten formulerar det $\mathrm{i}$ versaler som att "[P]ROJEKTETS HUVUDSYFTE ÄR ATTT TYDLIGT PÅVISA ATT SUGGESTOPEDIMETODEN GER EN SNABBARE SPRÅKINLÄRNING” (ESF-text 2). Målet här är att låta forskning visa att metoden fungerar. Detta ger forskningen en oväntad roll eftersom den har en öppen hållning inför att resultatet skulle kunna visa att metoden i själva verket ger en långsammare språkinlärning. På det viset reorganiseras en forskningspraktik. Fonden ger alltså pengar till projekt som har som ambition att förse forskning med ett empiriskt underlag som inte kan utsättas för ifrågasättanden.

Nästa fråga i det tredje analyssteget berör huruvida nätverket av praktiker ("the social order") "behöver" problemet? I den här studien är det möjligen inte hela nätverket som behöver problemet. Däremot kan man tänka sig att kommuner behöver lösningen. Vesterberg (2015) som särskilt har studerat ESF-projekt poängterar att välfärd numera ofta organiseras i projekt i vad han kallar "ongoing 'projectification' of welfare" (s. 303). Projekt som finansieras av Europeiska socialfonden kan alltså innehålla aktiviteter som i själva verket borde gå att genomföra $\mathrm{i}$ den ordinarie verksamheten. Tillägget för suggestopedimetoden skulle då kunna vara det (enda) som ger projektansökan ett innovativt intryck.

\section{Steg 4 - Motstridigheter, luckor och saknade motröster}

Som redan har nämnts uttrycker ESF-text 2 att syftet med projektet är "att tydligt påvisa att suggestopedimetoden ger en snabbare språkinlärning”. En sådan formulering kan ur ett forskningsperspektiv te sig något naiv och uttrycker en motstridighet mellan forskningens traditionella roll och förväntningar från projektaktörer. Ytterligare en motstridighet hittas i konstruktionen av dikotomin mellan den valda och förordade pedagogiken och den traditionella, en dikotomi som kan tyckas sökt. Dikotomin tycks här 
också inbegripa en förmodat irrelevant åtskillnad mellan det logiska och det kreativa.

En lucka handlar om att det inte anges vad det snabbare mäts i relation till, även om man kan förmoda att det gäller den traditionella SFI-undervisningen. Samma gäller de vaga påståenden som görs, till exempel i att deltagarna tillåts "visa upp fler sidor av sig själva" (Realtext 2). Inte heller här framgår vad man jämför med eller hur detta faktum relaterar till olika innehåll i undervisningen.

En av de intervjuade säger att "[v]issa kanske tycker att det låter flummigt men faktum är att metoden förenar många olika lärstilar" (Realtext 2, citat lärare). Lärstilsfenomenet är dock en myt (se Howard-Jones, 2014; De Bruyckere, Kirschner \& Hulshof, 2017). Myten om lärstilar ingår alltså inte bara som en ingrediens, utan tas också som intäkt för att metoden inte är 'flummig'. I samma artikel framkommer att 'läsningen sker till en speciellt utvald bakgrundsmusik, ett stycke av Mozart, med rätt antal slag per minut för att hålla elevernas sinnen alerta". Även denna så kallade Mozarteffekt inryms i neuromyter (Pietschnig, Voracek \& Formann, 2010; TokuhamaEspinosa, 2018). En saknad motröst är alltså den forskning som behandlar så kallade neuromyter.

Flera fenomen som framkommer i de studerade texterna har stött på forskningsbaserad kritik. Hit hör att de goda effekter som man vittnar om i urvalstexterna inte har kunnat påvisas i forskning (Shimbo, 2008). Att alla inte, som Mateva (1997) poängterar, tilltalas av rollspel är inte heller något som beaktas. Den anledning till detta faktum som Mateva framför tillhör förresten också neuromyterna, nämligen att motsträviga studenter "are predominantly analytic thinkers, left-hemispheric and grammatically-minded learners" (s. 29). Överhuvudtaget är de båda hjärnhalvornas olikheter en viktig förutsättning i suggestopedimetodiken; exempelvis Zaid (2014) poängterar att metoden aktiverar "the brain learning reserves latent in the process of brain lateralization (s. 114-115). Att studerande använder sina hjärnhalvor olika eller att de båda hjärnhalvorna behöver beaktas i undervisning är alltså en myt (se Corballis, 1980; Hines, 1987). Lozanov hävdade att elever bara använder fem till tio procent av sin mentala förmåga (se Larsen-Freeman, 2000) och att metoden snabbar på lärandet. Även detta antagande är dock att kategorisera som en myt enligt kritiska forskare (se Hughes, Lyddy \& Lambe, 2013). Även lärstilskonceptet som 'accelerated learning' bygger på (se Imel, 2002), har slagits fast vara en myt (se Gaussel \& Reverdy, 2013; Howard-Jones, 2014). Likaså har teorin om de multipla intelligenserna mött stark kritik (se till exempel Glazzard, 2015).

Att fenomenet 'infantilisering' som något förvånande betecknas som något positivt i suggestopeditraditionen också skulle kunna ha en baksida tycks ignoreras. Det innebär sammanfattningsvis att ytterligare en grupp kritiska forskares röst saknas. Likaså saknas deltagarnas röster och hur de upplever att delta i rollspel och leta vårtecken, något som sett $i$ ett 
språkundervisningsperspektiv bör betraktas som potentiellt svagt inramade aktiviteter. Detsamma skulle kunna sägas om projektens profiler mot hälsoinspirerande aktiviteter och liknande.

De aspekter som andraspråksforskning lyfter fram tycks därtill ges mindre betydelse. Till exempel undviks inte det bristperspektiv som Franker (2004) varnar för och inte heller beaktas i nämnvärd utsträckning deltagarnas behov av att utveckla komplicerade litteracitetsfärdigheter för formella sammanhang (www.skolverket.se).

\section{Steg 5 - Kritisk reflektion över den gjorda analysen}

I det här skedet uppmärksammar jag aspekter som kan försvaga värdet av den gjorda analysen. Till sådana aspekter hör att det vid sidan av hyllningar till metoden också uttrycks erkända problem. Dit hör invändningar som att suggestopedimetoden kanske inte tillräckligt stöder deltagarnas individuella skriftliga utveckling (Realtext 1, citat lärare).

Att urvalet i den här studien bygger på texter som har särskilda kännetecken är en annan aspekt. En glättig eller lekfull ton förväntas exempelvis lätt i en instagram-publicering och texter som projektansökningar/-beskrivningar har naturligt en vinst $i$ att dramatisera startläget. Beskrivningen av deltagarnas brister skulle därtill ha kunnat rättfärdigas av att det är ett vardagligt och mer naturligt och definitivt sätt att uttrycka sig på i texter som vill kontrastera det lyckade med projekt mot ett besvärligt utgångsläge. Oavsett bidrar ordval till en konstruktion av deltagare som maktlösa och som i avsaknad av strategier för att lära sig. Det senare är ett faktum som torde vara mindre sannolikt.

De konstateranden som görs i texterna skulle i själva verket ha kunnat uttryckas med sänkt modalitet, det vill säga i en alternativ formulering av typen "resultatet blir eventuellt en snabbare och bättre inlärning samt ett ökat självförtroende" (mitt tillägg i kursiv stil). Semiotiska resurser som Svenska ESF-rådets logotyp signalerar en myndighet och med det följer just förväntningar om en nedtonad och balanserad aktör.

En potentiell svaghet $\mathrm{i}$ den gjorda analysen är att lokalpressens artiklar bygger på ett urval av vad de intervjuade har sagt. Med utgångspunkt i krav på journalisters etiska förhållningssätt bör det dock inte finnas någon större anledning att tro att de intervjuades röster har blivit påfallande förvrängda. Inte heller finns det anledning att ifrågasätta de faktiska händelser som beskrivs, som att deltagarna exempelvis har gjort en faktisk utflykt på isen.

Man skulle kunna tro att ESF-texterna representerade de mest försiktiga texterna i jämförelse med realiseringstexterna. Så är dock inte självklart fallet. Medan en ESF-text i versaler konstaterar att "[p]rojektets huvudsyfte är att tydligt påvisa att suggestopedimetoden ger en snabbare språkinlärning" (ESFtext 2) är man mer försiktig i den motsvarande lokaltidningsartikeln där det anges att pedagogiken inte är "evidensbaserad, vilket rektor och klasslärarna hoppas att studien ska ändra på” (Realtext 2). Detta faktum torde stärka den 
gjorda analysen. Poängen med kritisk diskursanalys är för övrigt att nagelfara innehållet $\mathrm{i}$ alla sorters texter, även de som är medierade via olika typer av skribenter.

\section{DISKUSSION}

Den här artikeln har undersökt hur representanter för suggestopedimetodiken konstruerar vuxna med utomeuropeisk språkbakgrund samt hur deras framhållna problematik kan och bör bemötas enligt involverade projektaktörer. Resultatet har visat att texterna skriver fram ett problem som manifesteras i en traditionalitets- respektive bristdiskurs kring SFI-deltagare. Resultatet har också synliggjort att föreslagna lösningar vilar på en reklamrespektive lekfull antitraditionsdiskurs med svag vetenskaplig grund. Det framgår därtill att flera aktiviteter kan antas vara löst kopplade till verkningsfull språkundervisning och istället betonar värdlandets normer och värden. Ytterligare ett resultat är att ESF är en inflytelserik aktör i att förstärka vissa värden och antaganden.

Studien som har genomförts med en modifierad version av Faircloughs analysredskap har haft ett kritiskt perspektiv på antaganden om lärande i en suggestopediskt orienterad kontext. Viss tidigare forskning har lyft kritiska aspekter av metoden men den här studien har haft ambitionen att bidra med ytterligare, och fler konkreta, insikter om de diskurser som metoden vilar på i sin beskrivning av problem och lösningar, liksom vilket nätverksbygge som omgärdar metoden. Detta är i linje med Faircloughs diskursanalytiska angreppssätt som har som uppgift att synliggöra hur makt utövas diskursivt, i det här fallet i ett pedagogiskt sammanhang med konsekvenser främst för de studerande.

De valda projekten hör till en viss region i Sverige. Spridningen tycks dock vara kraftfull och artiklar om nystartade projekt i lokaltidningar är inte ovanliga ${ }^{9}$. På så vis utgör artikeln ett underlag för kommande diskussioner i en kontext av språkundervisning för vuxna med utländsk bakgrund.

\footnotetext{
NOTER

${ }^{1}$ https://www.esf.se/sv/Resultat/Projektbanken/Behallare-for-projekt/OstraMellansverige/KNUT/

${ }^{2}$ https://www.esf.se/sv/Resultat/Projektbanken-2014-2020/Alla-Projekt/SSI-

Suggestopedisk-SprakInlar/

${ }^{3}$ https://www.esf.se/sv/Resultat/Projektbanken-2014-2020/Alla-Projekt/Grona-

Gangen/

${ }^{4}$ Det finns 24 sådana i Sverige enligt artikeln.

${ }^{5}$ https:/ / tidningengrundskolan.se/de-dansar-och-smakar-pa-verben/
} 
${ }^{6}$ https://www.kkuriren.se/nyheter/katrineholm/lekfullheten-har-gjort-larandetlattare-sm4527129.aspx

${ }^{7}$ Man brukar arbeta med fyra; materiella, verbala, mentala och relationella.

${ }^{8}$ Den här processen är något svårtolkad. Hade det stått att "de har tragglat med svenskböckerna" hade jag kategoriserat det som en materiell, eller eventuellt verbal, process.

${ }^{9}$ Se till exempel

https://www.pressreader.com/sweden/hallandsposten/20180901/2815308168952 17

\section{TILLKÄNNAGIVANDE}

Arbetet med denna artikel har möjliggjorts med hjälp av Forskningsrådet för Interkulturell Dialog.

\section{REFERENSER}

Ayers, David Franklin (2005). Neoliberal ideology in community college mission statements: A critical discourse analysis. The Review of Higher Education, 28(4), 527549. DOI: $10.1353 /$ rhe. 2005.0033

Ball, Stephen (2016). Following policy: networks, network ethnography and education policy mobilities, Journal of Education Policy, 31(5), 1-18. https://doi.org/10.1080/02680939.2015.1122232

Brooks, Dennis R. (2003). A critical discourse analysis of a college faculty recruitment brochure. Studies about languages, (4), 32-39.

Colliander, Helena (2018). Being and Becoming a Teacher in Initial Literacy and Second Language for Adults. Linköping University, Department of Behavioural Sciences and Learning, 2018.

De Bruyckere, Pedro, Kirschner, Paul A. \& Hulshof, Casper D. (2017). Moderna myter om lärande och utbildning. Upplaga 1 Lund: Studentlitteratur

Fairclough, Norman (1995). Critical discourse analysis. London: Longman

Fairclough, Norman (2003). Analyzing discourse: Textual analysis for social research. London: Routledge.

Franker, Qarin (2004). Att utveckla litteracitet i vuxen alder - alfabetisering i en tvåsprakig kontext. I: Hyltenstam, Kenneth \& Lindberg, Inger, (red), Svenska som andrasprak - i forskning, undervisning och sambälle. Lund: Studentlitteratur, s. 675-713

Gaussel, Marie \& Reverdy, Catherine (2013). Neurosciences et éducation: la bataille des cerveaux. Dossier d'actualité Veille et Analyses IFÈ, n ${ }^{\circ 6}$, septembre. Lyon: ENS de Lyon. 
Glazzard, Jonathan (2015). A Critical Analysis of Learning Styles and Multiple Intelligences and their Contribution to Inclusive Education. Journal of Global Research in Education and Social Science, 2(3), 107-113.

Guo, Shibao (2010). Lifelong learning in the age of transnational migration. International Journal of Lifelong Education, 29(2), 14- 31. https://doi.org/10.1080/02601371003616509

Guo, Shibao \& Shan, Hongxia (2013). The politics of recognition: critical discourse analysis of recent PLAR policies for immigrant professionals in Canada. International Journal of Lifelong Education, 32(4), 464-480. https://doi.org/10.1080/02601370.2013.778073

Halliday, Michael (1994). An Introduction to Functional Grammar, 2nd edition, London: Edward Arnold.

Holmberg, Per \& Karlsson, Anna-Malin (2006). Grammatik med betydelse: en introduktion till funktionell grammatik. Uppsala: Hallgren \& Fallgren.

Howard-Jones, Paul (2014). Neuroscience and education: myths and messages. Nature Reviews Neuroscience, 15, 817-824. https://doi.org/10.1038/nrn3817

Hughes, Sean, Lyddy, Finoa, \& Lambe, Sinead (2013). Misconceptions about psychological science: A review, Psychology Learning and Teaching, 12(1), 20-31. http://dx.doi.org/10.2304/plat.2013.12.1.20

Imel, Susan (2002). "Accelerated Learning in Adult Education and Training and Development." Trends and Issues Alert, 33.

James, Ryan (2000). The Lozanov method/ accelerated learning and total immersion in adult second language learning: Teachers' reflections on the effectiveness of non-traditional methods. Dissertation. The Faculty of the School of Education International and Multicultural Education Department. The University of San Francisco.

Kress, Günther R. \& van Leuween, Theo (2006). Reading images: the grammar of visual design. London: Routledge.

Larsen-Freeman, Diane (2000). Techniques and Principles in Language Teaching. Teaching Techniques in English as a Second Language (2nd ed.). Oxford. Oxford University Press.

Leino, Lea (2017). A Study on the Promotion of Adults' Oral English Communication and Teacher Development in Liberal and Tertiary Education. Acta Universitatis Tamperensis 2258 Tampere University Press Tampere 2017.

Levinsson, Magnus \& Norlund, Anita (2018). En samtida diskurs om hjärnans betydelse för undervisning och lärande: Kritisk analys av artiklar i lärarfackliga tidskrifter. Utbildning \& Lärande, 12(1), s. 7-25.

Mateva, Galya (1997). The on-going role-play in suggestopedia. Language Learning Journal, 15 (1), 26-30. doi.org/10.1080/09571739785200061 
Norlund Shaswar, Annika (2014). Skriftbruk i vardagsliv och $i$ sfi-utbildning: En studie av fem kurdiska sfi-studerandes skriftbrukshistoria och skriftpraktiker. Umeå: Umea universitet.

Pietschnig, Jakob, Voracek, Martin \& Formann, Anton K. (2010). Mozart effect Shmozart effect: A meta-analysis.. Intelligence, 38(3), 314-323.

https://doi.org/10.1016/j.intell.2010.03.001

Rosén, Jenny (2014). 'Svenska för invandrare - mellan samhällsdeltagande och anställningsbarhet'. I M. Vinterek \& A. Arnqvist (Red.). Pedagogiskt arbete: Enhet och mångfald. Högskolan Dalarna, 95-112.

Scovel, Thomas (1979) Review Suggestology and Outlines of suggestopedy. TESOL Quarterly, 13(2), 255-266.

Schuster, Donald H. \& Gritton, Charles E. (1986). Suggestive accelerated learning techniques. New York: Gordon and Beach.

Shimbo, Kuninori (2008). The Effects of Music, Relaxation and Suggestion on Tertiary Students' Affect and Achievement in Learning Japanese as a Foreign Language. Australian Review of Applied Linguistics, 31(2), 16.1-16.22. https://doi.org/10.2104/aral0816

Straszer, Boglárka, Rosén, Jenny \& Wedin, Åsa (2020). Imagining the homeland: mother tongue tuition in Sweden as transnational space. Journal of Multicultural Discourses, 15(1), 42-60. https://doi.org/10.1080/17447143.2020.1726932

Tokuhama-Espinosa, Tracey (2018). Neuromyths: Debunking False Ideas about the Brain. New York: W. W. Norton \& Company.

Trigwell, Keith, Prosser, Michael \& Waterhouse, Fiona (1999). Relations between teachers'approaches to teaching and students'approaches to learning. Higher Education, 37(1), 57-70.

Trivette, Carol M., Dunst, Carl J., Hamby, Deborah W. \& O’Herin, Chainey E. (2009). Characteristics and consequences of adult learning methods and strategies. Research Brief Volume, 3(1), 1-33.

Vesterberg, Viktor (2015). Learning to be Swedish: governing migrants in labourmarket projects. Studies in Continuing Education (37)3, 302-316, DOI:10.1080/0158037X.2015.1043987

Wedin, Åsa, Rosén, Jenny \& Hennius, Samira (2018). Transsprakande och multimodalitet i grundläggande skriftspraksundervisning inom sfi, Pedagogisk Forskning i Sverige, (23)1-2, 15-38.

Wedin, Å., Rosén, J., Rasti, S., \& Hennius, S. (2016). Grundläggande litteracitet: Att undervisa vuxna med svenska som andraspråk.

Zaid, Mohamed A. (2014). Using suggestopedia in ELT in Saudi Arabia: Implications for Pedagogy. International Conference on Economics, Education and Humanities (ICEEH'14) Dec. 10-11, 2014 Bali (Indonesia) http://dx.doi.org/10.15242/ICEHM.ED1214088 